\title{
Transgenerational Genetic Effect of Trichloroethane (TCE) on Phenotypic Variation of Acrosomal Proteolytic Enzyme and Male Infertility Risk
}

\author{
Mohamed A. Al-Griw ${ }^{1,}$, , Naser M. Salama ${ }^{1}, \operatorname{Soad}_{\text {A. }}$ Treesh $^{2}$, Abdul Hakim Elnfati $^{1}$ \\ ${ }^{1}$ Division of Developmental Biology, Zoology Department, Faculty of Science, University of Tripoli, Tripoli, Libya \\ ${ }^{2}$ Department of Histology and Medical Genetics, Faculty of Medicine, University of Tripoli, Tripoli, Libya
}

Email address

m.algriw@zo.uot.edu.ly (M. A. Al-Griw), algriw_77@yahoo.com (M. A. Al-Griw)

\section{To cite this article:}

Mohamed A. Al-Griw, Naser M. Salama, Soad A. Treesh, Abdul Hakim Elnfati. Transgenerational Genetic Effect of Trichloroethane (TCE) on Phenotypic Variation of Acrosomal Proteolytic Enzyme and Male Infertility Risk. International Journal of Genetics and Genomics.

Vol. 3, No. 5, 2015, pp. 43-49. doi: 10.11648/j.ijgg.20150305.11

\begin{abstract}
Exposure to trichloroethane (TCE), a ambiguous environmental toxicant, has been negatively associated with male reproductive performance. The objective was to investigate, in-vivo, the mutagenic, carcinogenic or teratogenic effect of TCE maternal exposure on sperm quality and testicular cytoarchitecture of F1 generation of mice. A motile sperm separation technique was used to estimate sperm motility and a gelatin slide technique was used to measure the number of the halo around the acrosome of individual sperm as an acrosomal proteolytic enzyme (APA). Animals were followed up for signs of toxicity and mortality. Alterations in testicular tissues have been histopathology investigated. No adverse signs, symptoms and mortality were observed in the animals treated with TCE. Moreover, significant changes were seen in body and testis weight. Results of semen analysis revealed that TCE lead to low sperm count, abnormal sperm morphology, and frequently of sperm motility. These results were correlated with decrease in APA when pre-leptotene or spermatogonial cells were tested, indicating a transgenerational toxic effects. Histopathological examination revealed that TCE insult marked alterations in the microstructures of testicular tissues appeared as severe morphological abnormal spermatozoa and vacuoles. Taken together, these results suggest that early exposure to TCE causes testicular toxicity and poor semen quality. The sperm phenotypes utilized in this study may increase the value of sperm for detection mutagenic developmentally active agents, and agent with anti-fertility effects in mammals. This in-vivo animal model represents a unique platform for assessing human reproductive toxicity potential and genetic risk of various environmental mutagens, carcinogens and teratogens in a rapid, efficient, and unbiased format.
\end{abstract}

Keywords: Trichloroethane, Transgenerational Genetic Effect, Sperm Quality, Testicular Toxicity, Mice

\section{Introduction}

Environmental influences and insults by reproductive toxicant exposure can lead to impaired spermatogenesis or infertility. Understanding how toxicants disrupt spermatogenesis is critical for determining how environmental factors contribute to impaired fertility (8). Numerous environmental toxicants (e.g. cadmium, mercury, bisphenol A (BPA) and dioxin) have been reported to adversely affect spermatogenesis in rodents and humans, which can lead to low sperm count, abnormal sperm morphology and poor semen quality (9-11).

Trichloroethane (TCE), is widely used as an industrial solvent and a degreasing agent (12-14). It is reported that TCE is well absorbed by all exposure routes (15). Several studies with developmental exposure to lower doses than the "safe" dose suggest that TCE exposure can cause various detrimental defects, such as low fetal weight, birth defects, developmental disorders. Recently, it has been documented that chemical exposure environmentally or occupationally on a daily basis is associated with increase a risk of infertility, low fetal weights, and birth defects (15).

In general, the exposure during early embryogenesis or postnatal stage is important in the transgeneration of toxic effects (5). It has been indicated that following the direct exposure of $\mathrm{F} 0$ (F0 generation) pregnant rat about $90 \%$ of four generation males (F1-F4) had abnormal phenotype in testis and male germ cells, these effects increased by age to kidney disease, tumor development, prostate disease, immune abnormalities, and severe infertility $(3,5,7)$. These 
abnormalities were passed through male germ line, and not from females.

Exposure of mouse germ cells to radiation and chemicals results in mutation, malformation, cancer and other adverse effects (e.g., functional disorders) in the offspring, though these findings have not been proven in human studies (1). Traditionally, it is known that individual phenotypes result primarily from inherited genetic variants together with environmental exposures. However, several studies showed that a remarkable variety of factors including parental behaviors, maternal physiology, xenobiotics, nutritional supplements, environmental agents and others lead to epigenetic changes that can be transmitted to subsequent generations without continued exposure (2). The transfer of acquired heritable material or disease from parents to multiple subsequent generation through germ line known as "transgeneration" (3). Many studies have reported that exposure to environmental toxicants may promote the transition of abnormal phenotype between generations (4-5). The transgenerational phenomena of toxic effects involves the transmission of abnormal phenotype independently of direct exposure (6). Two possible mechanisms induce abnormal phenotype through transgeneration of toxic effects, the first is alteration in genetic material structure such as mutation and DNA sequence change, the second one includes the changing in epigenetic information such as histone acetylation and methylation, or DNA methylation $(3,5,7)$.

However, to our knowledge, until now there are little/ or no studies covering the transgenerational genetic effects of environmental toxicants on male reproductive function. Thus, the aim of this study was to investigate possible transgenerational toxic effects of TCE on microstructures of testicular tissues as well as sperm parameters of F1 mice.

\section{Materials and Methods}

\subsection{Animals, Housing and Treatment}

Four-week old female albino mice (19 - 23 g) were inbreed and housed in plastic cages on a bedding of wood chips at the Zoology Department (animal house) facility maintained at $\sim 22{ }^{\circ} \mathrm{C}, 50-60 \%$ relative humidity, and a 12 hours light/dark cycle. The animals were provided with standard lab chow and drinking water ad libitum and were acclimated for 1 week prior to the treatment. The animals were divided into four groups of six animals each, were treated with TCE [100 and $400 \mu \mathrm{g} / \mathrm{kg}$ in corn oil, i.p., every $3^{\text {th }}$ day $(13,16)$. The doses were calculated and delivered in $80-100 \mu$ corn oil based on their body weight. The vehicle controls were received an equal volume of corn oil only. However, the sham controls were not received any treatment. TCE at 100 and $400 \mu \mathrm{g} / \mathrm{kg}$ was selected according to the EPA (Environmental Protection Agency) as a safe dose (17). The treatment window was selected because this is the critical development window in the mouse (15).

During the course of the exposure period, animals were observed twice per day for any adverse clinical signs or abnormal behavior that may result from toxicity. The animals were weighed daily during the dosing period to adjust the administered dose for body weight changes.

At eight weeks of age, treated F0 females were mated with fertility confirmed control males. Mating was confirmed by the presence of vaginal plug. The day the vaginal plug was defined as gestation day-1 (GD-1). Once the vaginal plug was observed, females were removed from males and individually caged. F0 pregnant dams were observed daily and body weight was measured daily to further confirm pregnancy. The dams were allowed to deliver naturally and the delivery day was designed as PND-0.

After delivery, the size of each litter was standardized on PND-4 by eliminating extra pups through random selection within sex from litters with more than 10 pups to yield 10 pups, with five females and five males per litter. Natural litters with 10 or fewer pups were not standardized. F1 litter sizes, and weights, sex ratios, stillbirths, and percent of dead pups were recorded.

At three weeks of age, two F1 males from each litter were selected for examination of semen quality and testis. Moreover, at least one F1 male from each litter was selected to examine fertility. F1 males were housed with fertility confirmed control females. During the mating phase, all the females were weighed twice per week. Once the plug was observed, females were weighed and individually caged. Then, these females were monitored twice daily, and weighed twice per week until parturition. F2 litter sizes and weight as well as sex ratios and percent of dead pups were recorded on PND-1. After the three-week mating period, unmated males were singly housed and were considered as infertile males.

\subsection{Measurement of Body and Testis Weight}

Body and testis from the four groups were weighed before and at the end of the exposure period.

\subsection{Sperm Function Evaluation}

Spermatozoa were collected by mincing the epididymides in $37 \mathrm{C}^{\circ}$ normal saline from F1. Epididymal sperm counts and evaluation of the motility of epididymal sperms were performed as previous described (18-19) and the WHO manual for semen analysis (20). The examination of sperm morphology was carried out by dropping a drop of sperm suspension on a slide. After air dried, stained with $1 \%$ eosin $\mathrm{Y}$, washed and air dried again, the smears on the slides were observed under a light microscope (Leica, Germany).

\subsection{Acrosomal Proteolytic Activity (APA)}

A gelatin substrate film assay was used to assess the acrosomal proteolytic activity (APA) of individual spermatozoa, according to the method described previously $(18,21)$. This assay provides a visual demonstration of the release of enzyme from the acrosome of individual sperm. This technique is based on the principle that when sperm are incubated after smearing on the gelatin, the proteolytic enzyme in the acrosome digests the gelatin, making a halo 
around the acrosome as an indication of APA. The release of proteolytic enzyme from the intact acrosome of sperm is due to the evaporation procedure that causes ruptures of the plasma membrane, with consecutive disintegration of the acrosomal matrix. In brief, sperm suspension was washed thrice in $0.9 \%$ saline solution with $0.5 \%$ bovine serum albumin. On drop of sperm suspension was spread on the surface of glass slide coated with a thin layer of gelatin. The slides with sperm were incubated for one hour at $37^{\circ} \mathrm{C}$ in a wet chamber to allow proteolysis of the gelatin by acrosin and were fixed and then stained with toluidine blue. APA was indicated by a halo of unstained degraded protein around individual spermatozoa heads, sperm without activity lack an unstained halo. The percentage of sperm showing a halo was assessed by counting 200 sperm.

\subsection{Histological Studies}

At three weeks of age, to avoid litter effects, two F1 males per litter from each treatment group was euthanized by decapitation and the testis were collected for analysis.

Following dissection, 10\%-formalin-fixed testis were processed in a series of graded ethanol solutions and embedded in paraffin wax. Paraffin sections were cut at 6-8 $\mu \mathrm{m}$ thickness, deparaffinized, hydrated, stained with hematoxylin and eosin (H\&E) (22) and examined under a light microscope (Leica, Germany). All testicular histology was assessed blind by a histopathologist.

\subsection{Statistics}

Data were expressed as means \pm SEM from six female mice of each treatment group using SPSS software, version 20. A computerized Kolmogorov-Smirnov test was used to determine whether the data fitted a normal distribution. One-way ANOVA test followed by Tukey's post hoc comparisons was used to make multiple comparison between treatment groups. Student's t-tests were used to make comparisons between two groups. Mann-Whitney U-test was used for nonparametric samples. Statistical significance was assigned at $P \leq 0.05$.

\section{Results}

\subsection{Effect of TCE on Body and Testis Weight}

The statistical data in Table 1 showed that body and testis weight significantly $(P<0.05)$ changed in the TCE-treated groups compared to controls. The results showed that body weight in F1 males in $400 \mu \mathrm{g} / \mathrm{kg}$ TCE-treated group, but not $100 \mu \mathrm{g} / \mathrm{kg}$ TCE-treated group $(P=0.45)$ was significantly increased $(P=0.0013)$ comparing to controls (Table 1$)$. However, testis weight in F1 males in $400 \mu \mathrm{g} / \mathrm{kg}$ TCE-treated group, but not $100 \mu \mathrm{g} / \mathrm{kg}$ TCE-treated group $(P=0.24)$ was significantly decreased $(P=0.025)$ comparing to controls (Table 1). No significant changes were observed in body and testis weight in sham controls and vehicle controls (data not shown).
Table 1. The effects of TCE exposure on body and testis weight.

\begin{tabular}{lll}
\hline & Body weight $(\mathrm{g})$ & Testis weight $(\mathrm{g})$ \\
\hline Control & $23.33 \pm 1.03$ & $0.25 \pm 0.007$ \\
$100 \mu \mathrm{g} / \mathrm{kg} \mathrm{TCE}$ & $25.22 \pm 0.43$ & $0.23 \pm 0.008$ \\
$400 \mu \mathrm{g} / \mathrm{kg} \mathrm{TCE}$ & $29.4 \pm 1.03 \# \#$ & $0.18 \pm 0.021 \#$ \\
\hline
\end{tabular}

Data are mean \pm SEM ( $=6$ per group). Significance at $P \leq 0.05$. \# Significantly different from the controls.

\subsection{TCE Reduces Sperm Quality of F1 Mice}

Here we explored the effects of TCE insult on the sperm quality, count, motility, and morphology. The results showed that TCE at a dose of $100 \mu \mathrm{g} / \mathrm{kg}$ had no significant $(P=0.388$; Figure 1) effect on the count of cauda epididymal sperm comparing to controls. However, TCE exposure at a dose of $400 \mu \mathrm{g} / \mathrm{kg}$ has significantly $(P=0.033)$ decreased the sperm count of cauda epididymis comparing to controls (Figure 1).

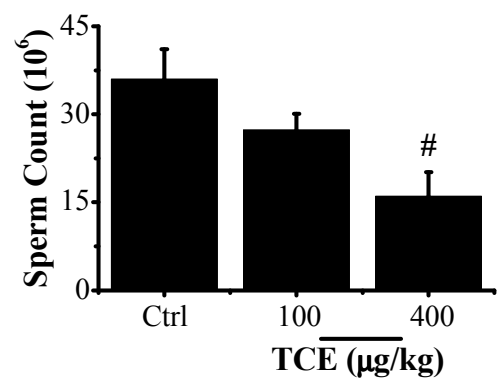

Figure 1. Effect of TCE insult on the count of cauda epididymal sperm of F1 mice. Quantification of sperm count. Data are expressed as the mean $\pm S E M$ $(n=6)$. \# Significantly different from the controls $(P \leq 0.05)$.

Next, we investigated the effect of TCE insult on the sperm motility of caudal epididymis in-vitro. Sperm motility seemed significantly $(P<0.05)$ changed in TCE-treated groups compared to controls (Figure 2). Specifically, $100 \mu \mathrm{g} / \mathrm{kg}$ TCE treatment group showed lower $(P=0.049)$ percent of motile sperm compared to controls (Figure 2). The results also showed that the percent of immotile sperm induced by 400 $\mu \mathrm{g} / \mathrm{kg}$ TCE $(\sim 55 \%)$ was greater than observed with $100 \mu \mathrm{g} / \mathrm{kg}$ TCE $(\sim 41 \%)$. Moreover, there was no significant difference in the percent of motile sperm between 100 and $400 \mu \mathrm{g} / \mathrm{kg}$ TCE treatment groups (Figure 2).

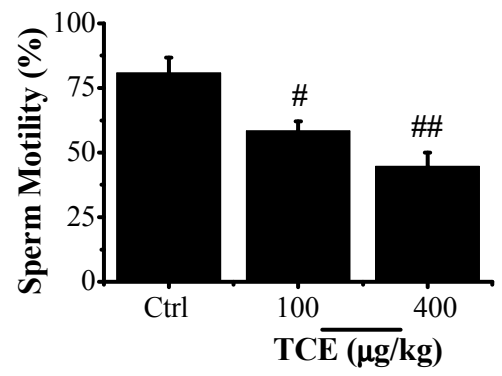

Figure 2. Effect of TCE insult on the motility of cauda epididymal sperm of F1 mice. Quantification of sperm motility. Data are expressed as the mean $\pm S E M$ $(n=6)$. \#Significantly different from the controls $(P \leq 0.05)$.

Regarding the morphology of cauda epididymal sperm of F1 mice, TCE insult had a harmful effect on the sperm 
morphology in TCE-treated groups compared to controls (Figure 3). The sperm morphology were shown in Figure 3A from which no head sperm, sticky sperm and sperms with coiled tail were observed in the TCE-treated groups. Sperm head-tail detachment and sperm tail fragmentation were most commonly observed abnormalities by microcopy in cauda epididymal spermatozoa of TCE-exposed F1 mice (Figure 3 A). Sperm fragmentation was not commonly observed after TCE treatment (Figure 3A). Common defects in the TCE groups/set included sperm head malformations (Figure 3A) and a pattern of longitudinal bundling of seemingly morphologically normal spermatozoa (Figure 3A).

The statistical analysis showed that the percent of abnormal cauda epididymal sperm in the TCE-treated groups was significantly increased compared to controls (Figure 3B). Specifically, in $100 \mu \mathrm{g} / \mathrm{kg}$ TCE-treated group showed lower $(P=0.000025)$ abnormal sperm compared to $400 \mu \mathrm{g} / \mathrm{kg}$ TCE-treated group (Figure 3B).
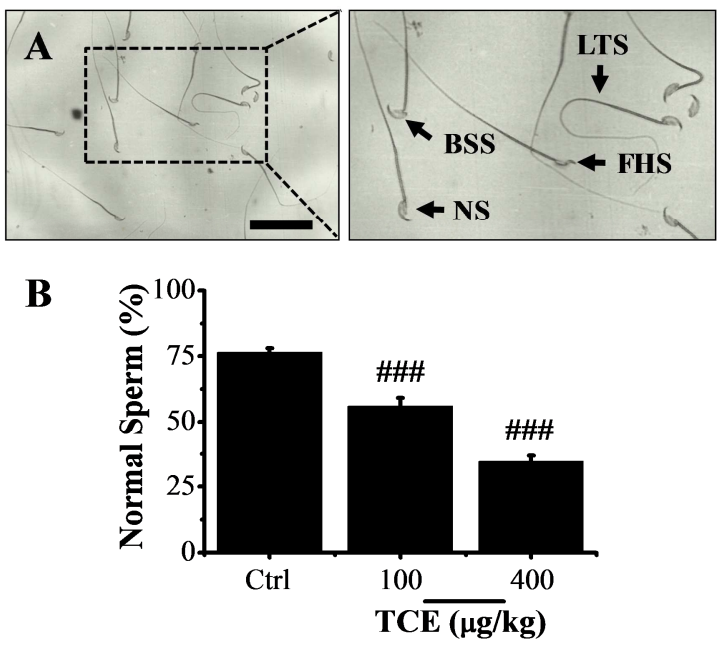

Figure 3. Sperm morphology after TCE insult. (A) Photomicrograph of morphology of the cauda epididymal sperm of F1 mice treated parents showing normal sperm (NS), fused head sperm (FHS), banana shape sperm (BSS), loose tail sperm (LTS), and tight tail sperm (TTS). The magnification is $X 400$. Scale bar $=20 \mu \mathrm{m}$. (B) Quantification of normal sperm in response to TCE exposure. Data are expressed as the mean $\pm \operatorname{SEM}(n=6)$. \# Significantly different from the controls $(P \leq 0.05)$.

\subsection{Effects of TCE on Sperm Acrosome Reaction}

Here we characterized, in-vitro, the impact of TCE insult on the caudal epididymis sperm. Sperm from the caudal epididymis produced halos on gelatin substrate slides (Figure 4A). The motility of cauda epididymal sperm seemed unchanged in sham controls compared to vehicle controls (data not shown). Gelatin substrate film assay was conducted to assess APA of individual sperm. The heads of $\sim 75 \%$ of sperm from controls had protein-digested halos generated by acrosin activity on the gelatin substrate films. By contrast, only the heads of $\sim 37 \%$ and $30 \%$ of sperm from 100 and 400 $\mu \mathrm{g} / \mathrm{kg}$ TCE-treated groups, respectively, had protein-digested halos generated by acrosin activity on the gelatin substrate films (Figure 4B), meaning that proteolytic activity is inhibited by TCE insult.
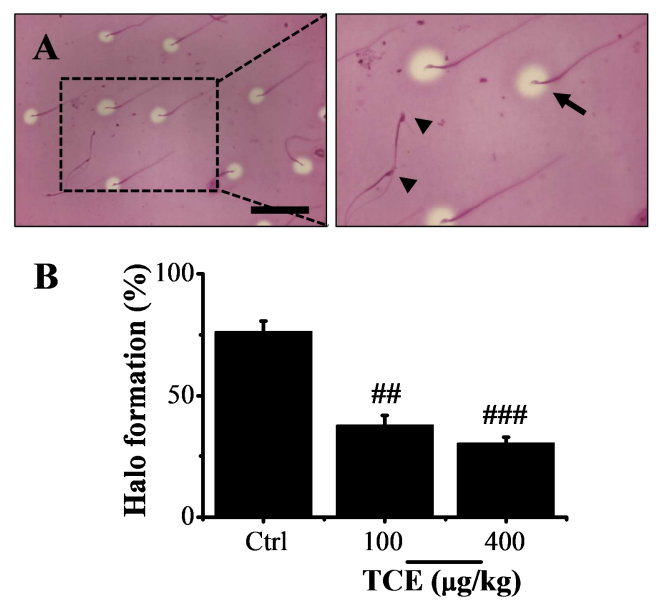

Figure 4. Sperm motility after TCE insult. (A) Photomicrograph of motility of the cauda epididymal sperm of F1 mice treated parents showing haloes of unstained degraded protein around individual spermatozoan heads (arrow) and sperm with acrosomal proteolytic activity (no haloes; arrowhead). The magnification is X100. Scale bar $=20 \mu \mathrm{m}$. (B) Quantification of halo formation in response to TCE exposure. Data are expressed as the mean \pm S.E.M ( $n=6$ per group). \# Significantly different from the controls $(P \leq 0.05)$.

\subsection{TCE Insult Alters Cytoarchitecture of the Testicular Tissue of F1 Mice}

To explore the effect of TCE insult on the microstructures of testicular tissues of F1 mice, we performed histopathological evaluations. Microscopic observation of the testicular tissues by $\mathrm{H} \& \mathrm{E}$ staining revealed that normal morphology and cellular arrangement of seminiferous tubules appeared in the control (Figure 5A-B). Moreover, closely packed seminiferous tubules, separated from each other by narrow interstitial spaces containing interstitial Leydig cells around blood capillaries. These seminiferous tubules were lined by spermatogenic and Sertoli cells. The spermatogenic cells were formed of spermatogonia, primary spermatocytes and spermatids. The spermatogonia appeared as small cells Spermatogonia with dark, ovoid nuclei, these cells are located basally in the epithelium next to the basement membrane. complete spermatogenesis and regular structure, many spermatozoa present in disorganized tubules.

In contrast, there was morphological abnormal spermatozoa and vacuoles in the TCE-treated groups. Testicular tissues from the $100 \mu \mathrm{g} / \mathrm{kg}$ TCE-treated group showed disorganization in some seminiferous tubules, cellular irregularity and large vacuolization between spermatogenic cells and intracellular, also a thickness in basement membrane of spermatogenic epithelium were observed in some tubules (Figure 5C-D).

Further analysis showed that the testicular tissues of 400 $\mu \mathrm{g} / \mathrm{kg}$ TCE-treated group showed degenerative changes in all seminiferous tubules with a few germ cells in the lumen and marked intercellular and basal vacuolation, detachment of spermatogonia from the basement membrane and separation between germinative cells in the seminiferous tubules (Figure 5E-F). In some seminiferous tubules there are slightly reduction in density of germinal cells. There was also disruption to the arrangement of Sertoli cells and germinal cells and increasing space between them. Degeneration in 
Leydig cells were also observed. No spermatogenesis in the lumen of seminiferous tubules were observed.

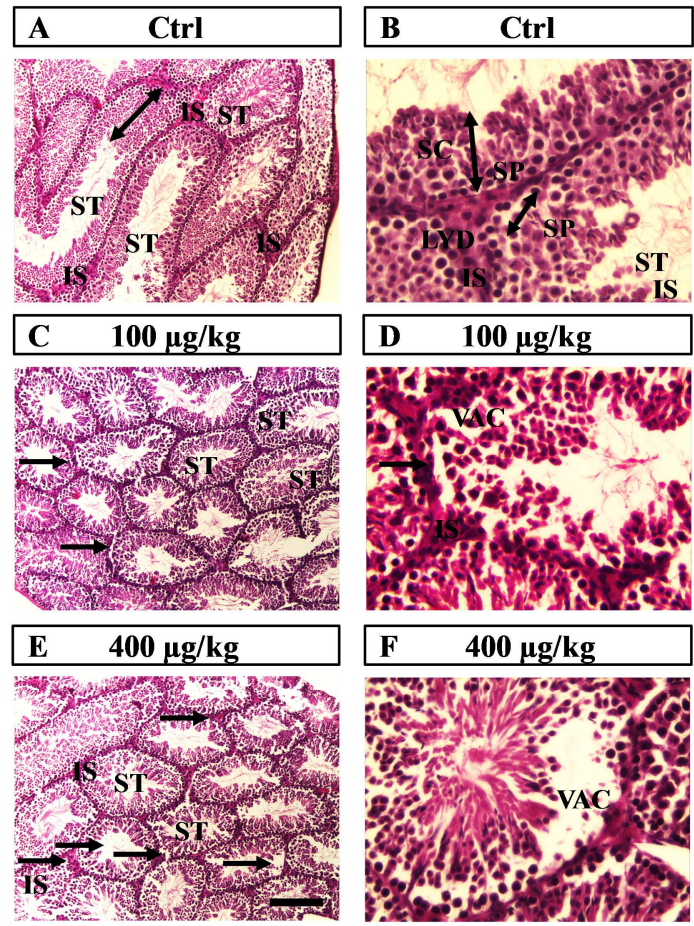

Figure 5. The effect of TCE insult on microstructures of testicular tissues of $F 1$ mice observed by $H \& E$ staining. (A-B) A photomicrograph of a testicular tissue of control showing (A) closely packed seminiferous tubules (ST), lined by normal spermatogenic cells $(\leftrightarrow)$, Leydig cells (LYD) within interstitial spaces (IS). (B) The STs were lined by spermatogenic cells and Sertoli cells $(S C)$, spermatozoa (SP) present in the lumen. (C-D) A photomicrograph of a testicular tissue of $100 \mu \mathrm{g} / \mathrm{kg}$ TCE-treated group showing $(C)$ detachment of spermatogonia from the basement membrane $(\rightarrow)$ and $(D)$ intercellular vacuolations (VAC). (E-F) A photomicrograph of a testicular tissue of 400 $\mu \mathrm{g} / \mathrm{kg}$ TCE-treated group showing; (E) Affected ST with detachment of spermatogonia from the basement membrane $(\rightarrow)$ and intercellular VAC. $(F)$ complete loss of spermatogenic cells (VAC). (A, C, E; X10). (B, D, F; X40). Scale bar $=50 \mu \mathrm{m}$.

\section{Discussion}

Infertility caused by exposure to many environmental toxicants is a global problem, particularly in industrialized countries (23). The environmental toxicants, such as vinclozolin, bisphenol A and phthalates have the ability to induce changes in the genetics and the epigenetics of male germ line, and promote the transgenerational inheritance that affect male fertility $(3,7,24)$.

The male reproductive system has emerged as one of the major toxicity targets of environmental toxicants. Although acute exposure of toxicants contributes to apoptosis and necrosis of testicular cells, chronic and sub-lethal exposure is prevailing in the general public $(23,25)$. Due to the unusual long half-lives of some of these toxicants in mammalian body (e.g. cadmium has a mean half-life of 15 years (26), chronic and low level exposure to humans could cause long-term unwanted health effects. In-vivo studies are crucial to assess toxicants with adverse effects on human health.

The purpose of the present study was to evaluate, in-vivo, the long-term effect of TCE exposure on sperm APA, sperm motility, sperm morphology and sperm count. Although, TCE has been classified as non carcinogenic (group-3), because there is inadequate evidence for carcinogenicity in both human and animals (27-29), many reports indicated that TCE bound with DNA, RNA and proteins in many organs such as liver, kidney, lung and stomach in F0 mice and rats following a single intraperitoneal injection, but did not induce any abnormal changes (30-31). Based on these finding, this study suggested that TCE might induce transgenerational inheritance in the genetic and epigenetic of male germ line. The result of this study indicated that the spermatogenesis of F0 was slightly affected by TCE, it significantly decreases the total count of sperms in treated groups, these finding similar to previous result of many reports (32). However, in F1 the figure of spermatogenesis parameters was completely different, the result showed important histopathologic finding in testis, decreases in sperm count, abnormal acrosome reaction and teratogenic sperms.

The proper functioning of the flagellum and acrosome of sperm is vital for the process of fertilization and thus determines fertility potential of the sperm (33). One of the more elusive questions in genotoxic research is whether a change in sperm phenotype following treatment with a suspected mutagen is due to mutation or developmental disturbance. However, the effects of TCE exposure on male reproduction in later reproductive life are unclear. The results of this study showed that the induced loss sperm motility and APA in single spermatozoa derived from TCE-treated mice is caused by mutational or developmental effects. Gene mutation/s induced in spermatogonial cells and spermatogonial stem cells could readily be transmitted through cell cycle to be induced and expressed in spermatozoa. That environmental toxicant TCE is capable of inducing gene and chromosomal mutations in spermatogonial cells are unclear. The findings of this study suggest that TCE treatment of these stages therefore probably interferes with the expression of existing gene products (18).

Exposure to different classes of environmental toxicants can disrupt male reproductive function by affecting the endocrine system, by changing gene expression that is pertinent to spermatogenesis and steroidogenesis and by exerting epigenetic effects, which can result in abnormalities in the reproductive system of male offspring up to four generations following in utero exposure (23).

When referring to the testicular toxicity induced by environmental toxicant TCE, (34-35) indicate that the administration of TCE has no impact on the weights of body and testis in mice but can induce spermatogenic damage and affect sperm counts and sperm motility. In contrast, in this study we found that early exposure to TCE had significant effect on the body and testis weight. Therefore, histopathologic analysis of testis and epididymis showed that an extensive emptying of the tubular germinal elements into the epididymis. Since $90 \%$ of the volume of the testis is seminiferous tubules (36), the extensive loss of germinal cells from these tubules may account for the $50 \%$ decrease in testis weight. Along with their 
indications, the sperm toxicity tests also reveal that sperm count, motility and normal sperms were sharp reduction in the TCE-treated mice. The decrease in the body weight may be caused by the decline of food intake and the reduction in the testicular weight is attributed to the necrotic changes in the testis (37-38). Accordingly, we consider that the observed abnormal features in the testis tissues by $\mathrm{H} \& \mathrm{E}$ analysis are responsible for the decreased testicular weight.

It is well known that histological assays are reliable tools to detect morphological changes due to toxicants; hence, the histopathology of various treated tissues was examined. The abnormal features in the testis and the aberrant sperm parameters are reported to result from the reactive oxygen species (ROS) (39). However, it has been found that the supplementation of vitamins $\mathrm{C}$ and $\mathrm{E}$ can't recover the body and testis weights decreased by exposure to environmental toxicants and have no efficiently alleviating effects on the sperm toxicity. Concerning the situation in the paper, the factors can be complicated. One of them may be that the ROS induced by TCE exposure may be not the sole reason leading to the damage of testis. Additional studies comparing low level chronic exposure versus high level acute exposure to environmental toxicant TCE are also required to elucidate fully the underlying molecular mechanism by which this toxicant disrupts male reproductive function.

In conclusion, the present study finds that the TCE exposure can cause serious testicular toxicity. Since a low sperm count is correlated with decreased sperm quality and acrosomal integrity, which is essential for penetration of the zona pellucida by sperm. The presence of these sperm phenotypes may help to detect chemicals with anti-fertility effects. This study offers a framework to possibly develop approaches to therapeutically treat and/or manage the damaging effects of environmental toxicants to male reproductive health.

\section{Acknowledgement}

This investigation was supported in part by the Division of Developmental Biology, Faculty of Science, University of Tripoli, Tripoli, Libya.

\section{References}

[1] Sadowski, R. N., Wise, L. M., Park, P. Y., Schantz, S. L., Jurask, J. M. (2014) Early Exposure to Bisphenol A alters Neuron and Glia Number in the Rat Prefrontal Cortex of Adult Males, but not Females, Neuroscience 279, 122-131.

[2] Nomura, T. (2008) Transgenerational effects from exposure to environmental toxic substances, Mutation Research 659 185-193.

[3] Nadea, J. H. (2009) Transgenerational genetic effects on phenotypic variation and disease risk, Human Molecular Genetics 18, R202-R210.

[4] Anway, M. D., Cupp, A. S., Uzumcu, M., and Skinner, M. K. (2005) Epigenetic transgenerational actions of endocrine disruptors and male fertility, Science 308, 1466-1469.
[5] Rakyan, V., and Whitelaw, E. (2003) Transgenerational epigenetic inheritance, Curr Biol 13, R6.

[6] Anway, M. D., Memon, M. A., Uzumcu, M., and Skinner, M. K (2006) Transgenerational effect of the endocrine disruptor vinclozolin on male spermatogenesis, $J$ Androl 27, 868-879.

[7] Skinner, M. K. (2007) Endocrine disruptors and epigenetic transgenerational disease etiology, Pediatr Res 61, 48R-50R.

[8] Anway, M. D., Leathers, C., and Skinner, M. K. (2006) Endocrine disruptor vinclozolin induced epigenetic transgenerational adult-onset disease, Endocrinology 147, 5515-5523.

[9] Easley IV, C. A., Bradner, J. M., Mosera, A., Rickmana, C. A., McEachina, Z. T., Merritt, M. M., Hansenc, J. M., and Caudle, W. M. (2015) Assessing reproductive toxicity of two environmental toxicants with a novel in vitro human spermatogenic model, Stem Cell Research 14, 347-355.

[10] Aitken, R. J., Koopman, P., and Lewis, S. E. M. (2004) Seeds of concern, Nature 432, 48-52.

[11] Wong, E. W. (2010) Cell junctions in the testis as targets for toxicants. In: Richburg, JH.; Hoyer, P., editors., Comprehesive toxicology. Academic Press, P167-188.

[12] Sharpe, R. M. (2010) Environmental/lifestyle effects on spermatogenesis, Philos Trans R Soc Lond B Biol Science 365, 1697-1712.

[13] House, R. A., Liss, G. M., Wills, M. C., Holness, D. L. (1996) Paresthesias and sensory neuropathy due to 1,1,1-trichloroethane, Journal occupational environmental Medicine 38, 123-124.

[14] Wang, G., Cai, P., Ansari, G. A. S., and Khan, M. F. (2007) Oxidative and nitrosative stress in trichloroethene-mediated autoimmune response, Toxicology 229, 186-193.

[15] York, R. G., Sowry, B. M., Hastings, L., Manson, J. M. (1982) Evaluation of teratogenicity and neurotoxicity with maternal inhalation exposure to methyl chloroform, Journal of Toxicol. environ. Health 9, 251-266.

[16] Wang, W., Hafner, K. S., and Flaws, J. A. (2014) In utero bisphenol A exposure disrupts germ cell nest breakdown and reduces fertility with age in the mouse, Toxicology and Applied Pharmacology 276, 157-164.

[17] Khan, M. F., Kaphalia, B. S., Prabhakar, B. S., Kanz, M. F., and Ansari, G. A. (1995) Trichloroetheneinduced autoimmune response in female MRL $+/+$ mice, Toxicology Applied Pharmacology 134, 155-160.

[18] Lane, R. W., Riddle, B. L.; Borzelleca, J. F. (1982) Effects of 1,2-dichloroethane and 1,1,1-trichloroethane in drinking water on reproduction and development in mice., Toxicol Appl Pharmacology 63, 409-421.

[19] Salama, N. M., Ficsor, G., Block, K. K., McIntire, C. L., and Ginsberg, L. C. (1982) Germ cell specific decrease of acrosomal proteolytic activity, sperm motility and number in Mitomycin C treated mice, Teratogenic and Carcinogenic 2, 13-18.

[20] Zhang, H., Wang, H., Ji, Y. L., Ning, H., Yu, T., Zhang, C., Zhang, Y., Zhao, X. F., Wang, Q., Liu, P., Meng, X. H., Xu, D. X. (2009) Lactational fenvalerate exposure permanently impairs testicular development and spermatogenesis in mice, Toxicol Lett 191, 47-56. 
[21] Organization, W. H. (1999) WHO laboratory manual for the examination of human semen and sperm-cervical mucus interaction. 4th ed. Cambridge: Cambridge University Press, $128 \mathrm{p}$.

[22] Ginsberg, L. C., Johnson, S. C., Salama, N. M., and Ficsor, G. (1981) Acrosomal proteolytic assay for detection of mutagens in mammals, Mutation Research 91, 413-418.

[23] Bancroft, J. D., and Gamble, M. (2008) Theory and practice of histological techniques. 6th ed. Philadelphia, PA: Churchill Livingstone.

[24] Wong, E. W. P., and Cheng, C. Y. (2011) Impacts of environmental toxicants on male reproductive dysfunction, Trends Pharmacol Science 32, 290-299.

[25] Manikkam, M., Guerrero-Bosagna, C., Tracey, R., Haque, M. M., and Skinner, M. K. (2012) Transgenerational actions of environmental compounds on reproductive disease and identification of epigenetic biomarkers of ancestral exposures, PLoS One 7, e31901.

[26] Hauser, R., and Sokol, R. (2008) Science linking environmental contaminant exposures with fertility and reproductive health impacts in the adult male, Fertil Steril 89 , e59-65.

[27] Kjellstrom, T., and Nordberg, G. F. (1978) A kinetic model of cadmium metabolism in the human being, Environ Research 16, 248-269.

[28] EPA. (2007) Toxicological Review of 1,1,1-Trichloroethane (CAS No. 71-55-6) In Support of Summary Information on the Integrated Risk Information System (IRIS), EPA/635/R-03/013. U.S. Environmental Protection Agency, Washington, DC. .

[29] WHO. (2003) 1,1,1-Trichloroethane in Drinking-water. Background document for development of

[30] WHO Guidelines for Drinking-water Quality., World Health Organization WHO/SDE/WSH/03.04/65., 16.

[31] ASTDR. (2006) 1,1,1 Trichloroethane, Agency for Toxic Substances and Disease Registry, 371.

[32] Prodi, G., Collacci, A., and Grilli, S. (1988) Comparison of the covalent binding of various chloroethanes with nucleic acids.
In: Feo, F; ed. Chemical carcinogenesis: models and mechanisms. , PNew York, NY: Plenum Press; . 93-102.

[33] Turina, M., Colacci, A., and Grilli, S. (1986) Short-term tests of genotoxicity for 1,1,1-trichloroethane. , Res Commun Chem Pathol Pharmacol 52, 305-320.

[34] NTP. (2000) NTP technical report on the toxicity studies of 1,1,1-trichloroethane administered in microcapsules in feed to F344/N rats and B6C3F1 mice. , National Toxicology Program. (41) NIH 004402.

[35] Ahammad, M. U., Nishino, C., Tatemoto, H., Okura, N., Kawamoto, Y., Okamoto, S., and Nakada, T. (2011) Maturational changes in motility, acrosomal proteolytic activity, and penetrability of the inner perivitelline layer of fowl sperm, during their passage through the male genital tract, Theriogenology 76, 1100-1109.

[36] Quast, J. F., Calhoun, L. L., Frauson, L. E. (1988) 1,1,1-trichloroethane formulation: a chronic inhalation toxicity and oncogenicity study in Fischer 344 rats and B6c3F1 mice Fundamental and applied toxicology: official journal of the Society of Toxicology 11, 611-625.

[37] Adams, E., Spencer, H., Rowe, V. (1950) Vapor toxicity of 1,1,1-trichloroethane (methylchloroform) determined by experiments on laboratory animals, Arch Ind Hyg Occup Med 2, 225-236.

[38] Shire, J. G. M., and Bartke, A. (1972) Strain differences in testicular weight and spermatogenesis with special reference to C57HL/10J and DBA/2J mice., Journal of Endocrinology 55, 163-171.

[39] Joshi, S. C., Mathur, R., Gulati, N.. (2007) Testicular toxicity of chlorpyrifos (an organophosphate pesticide) in albino rat, Toxicol Ind Health 23, 439-444.

[40] ElMazoudy, R. H., Attia, A. A., El-Shenawy, N. S. (2011) Protective role of propolis against reproductive toxicity of chlorpyrifos in male rats, Pestici Biochem Phys 101, 175-181.

[41] Wu, P. F., Chiang, T. A., Chen, M. T., Lee, C. P., Chen, P. H., Ko, A. M., Yang, K. J., Chang, P. Y., Ke, D. S., Ko, Y. C. A. J. (2010) characterization of the antioxidant enzyme activity and reproductive toxicity in male rats following sub-chronic exposure to areca nut extracts, Hazard Mater 178, 541-546. 